\title{
Síntese e estabilização do Hidróxido de Cobre (II) preparado em solução aquosa livre de surfactantes
}

\author{
Machado, I. P. 1*; Merízio, L. G. ${ }^{2}$; Muri, E. J. B. ${ }^{2}$; Marins, A. A. L. ${ }^{2}$ Machado, L. C.²; \\ Passos, C. A. C. ${ }^{3} ;$ Abílio, V. T. ${ }^{3}$; Rodrigues, R. V. ${ }^{1}$ \\ 1 Instituto de Química, Universidade de São Paulo, IQ-USP , São Paulo, SP, Brasil \\ 2 Departamento de Química, Universidade Federal do Espírito Santo, DQUI-UFES, Vitória, ES, Brasil \\ 3 Departamento de Física, Universidade Federal do Espírito Santo, DFIS-UFES, Vitória, ES, Brasil
}

\begin{abstract}
Resumo
Esse trabalho consistiu na preparação e estabilização do Hidróxido de Cobre (II) a partir da simples adição de uma solução de $\mathrm{NaOH}$ à soluções aquosas de $\mathrm{CuCl}_{2} \mathrm{e} \mathrm{CuSO}_{4}$ à temperatura de $10^{\circ} \mathrm{C}$. Os efeitos da concentração de $\mathrm{Cu}^{2+} \mathrm{e}$ da adição de amônia também foram investigados. Após os procedimentos de síntese, os seis produtos obtidos foram lavados e secos a vácuo. Os ensaios de Análise Termogravimétrica (TG) indicaram diferenças sutis nas curvas de perda de massa dos produtos, sugerindo que os géis produzidos na presença de $\mathrm{NH}_{3}$ mais estáveis. Os resultados da Difratometria de Raios-X (DRX) indicaram a fase ortorrômbica do $\mathrm{Cu}(\mathrm{OH})_{2}$ para todos os produtos, sem a presença de impurezas. Verificou-se que o gel mais estável foi o produzido a partir de $\mathrm{CuCl}_{2}$ na presença de amônia: apresentou maior cristalinidade e maior tempo de estabilidade (2 meses), quando comparado com os demais, sugerindo a importância do contra-íon e da amônia na formação e estabilização do Hidróxido de Cobre.
\end{abstract}

Palavras chaves: Hidróxido de Cobre, Síntese, Termogravimetria.

\section{Introdução}

O Hidróxido de Cobre (II), $\mathrm{Cu}(\mathrm{OH})_{2}$, é um material que apresenta diversas aplicações, por exemplo em

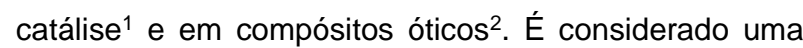
fase metaestável, pois converte-se espontaneamente a $\mathrm{CuO}$ no estado sólido a $150^{\circ} \mathrm{C}$ e em solução aquosa a temperatura ambiente. ${ }^{4}$ Por esse fato, é um potencial precursor dos óxidos de cobre, largamente empregados como semicondutores, precursores de cerâmicas, eletrodos e sensores de gás. ${ }^{1,3,4}$

A síntese do $\mathrm{Cu}(\mathrm{OH})_{2}$ envolve principalmente métodos sol-gel e o uso surfactantes, com a finalidade de controlar a forma e o tamanho de partícula. ${ }^{1,3,5}$ Entretanto essas práticas não visam a obtenção do material puro. Desse modo, o objetivo desse trabalho consistiu em preparar e estabilizar $\mathrm{O} \mathrm{Cu}(\mathrm{OH})_{2}$ partindo de rotas simples em solução aquosa, dispensando o uso de surfactantes para obter produtos puros.

\section{Materiais e Métodos}

As seis rotas de síntese desenvolvidas estão apresentadas na tabela 1 . O procedimento de síntese consistiu na adição estequiométrica de uma solução $\mathrm{NaOH} 1,0$ mol.L-1 às soluções de $\mathrm{Cu}^{2+}$ descritas na tabela, seguida de 5 minutos de agitação constante. A adição de $5 \mathrm{~mL}$ de $\mathrm{NH}_{3}$ concentrada foi feita nas rotas 3 , 4,5 e 6 . Todas as reações foram feitas a $10^{\circ} \mathrm{C}$.

\begin{tabular}{cccc}
\hline Rota & $\begin{array}{c}\text { Precursor } \\
\text { de Cobre }\end{array}$ & $\begin{array}{c}\text { Concentração } \\
\text { (mol.L-1) }\end{array}$ & $\begin{array}{c}\text { Adição } \\
\text { de NH}\end{array}$ \\
\hline $\mathbf{1}$ & $\mathrm{CuCl}_{2}$ & 0,1 & Não \\
\hline $\mathbf{2}$ & $\mathrm{CuCl}_{2}$ & 0,5 & Não \\
\hline 3 & $\mathrm{CuSO}_{4}$ & 0,1 & $\mathrm{Sim}$ \\
\hline 4 & $\mathrm{CuSO}_{4}$ & 0,5 & $\mathrm{Sim}$ \\
\hline 5 & $\mathrm{CuCl}_{2}$ & 0,1 & $\mathrm{Sim}$ \\
\hline 6 & $\mathrm{CuCl}_{2}$ & 0,5 & $\mathrm{Sim}$ \\
\hline
\end{tabular}

Tabela 1: Rotas de síntese adotadas. 
Após $24 \mathrm{~h}$ de repouso em geladeira, os seis produtos obtidos foram lavados com água deionizada gelada, com auxílio de uma centrífuga, e secos a vácuo por 6 h.

Em seguida foram submetidos aos ensaios de TG em um TA Instruments modelo SDTQ600, com rampa de aquecimento de $10^{\circ} \mathrm{C} \cdot \mathrm{min}^{-1}$ até $1000^{\circ} \mathrm{C}$ e atmosfera dinâmica de ar sintético, e DRX pelo método do pó em um Bruker D8 Discover (radiação Cu Ka $\lambda=1,5418 \AA \AA$ ).

\section{Resultados e Discussão}

Estão apresentadas nas figuras 1 e 2, respectivamente, as curvas termogravimétricas e os difratogramas de raios- $\mathrm{X}$ dos $\mathrm{Cu}(\mathrm{OH})_{2}$ produzidos pelas seis rotas.

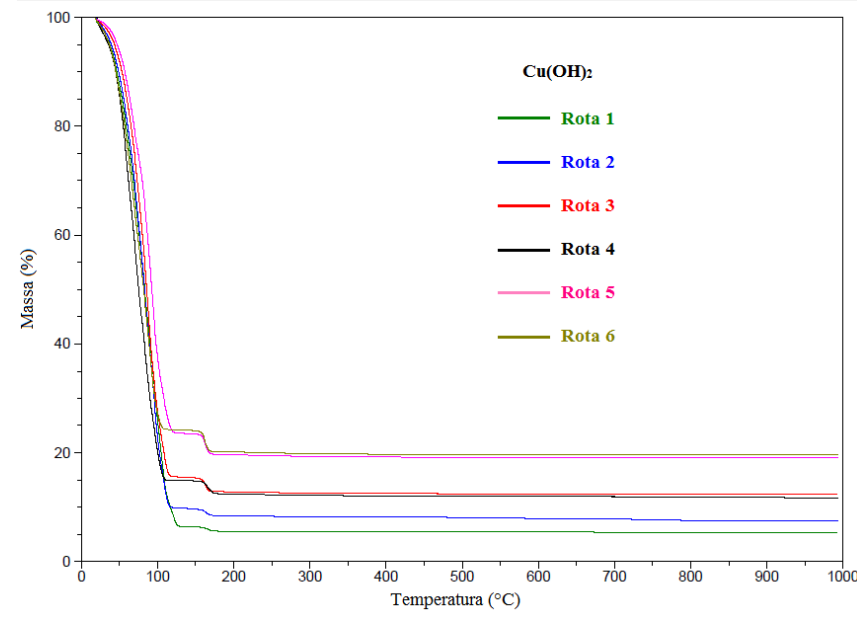

Figura 1: Curvas termogravimétricas dos produtos.

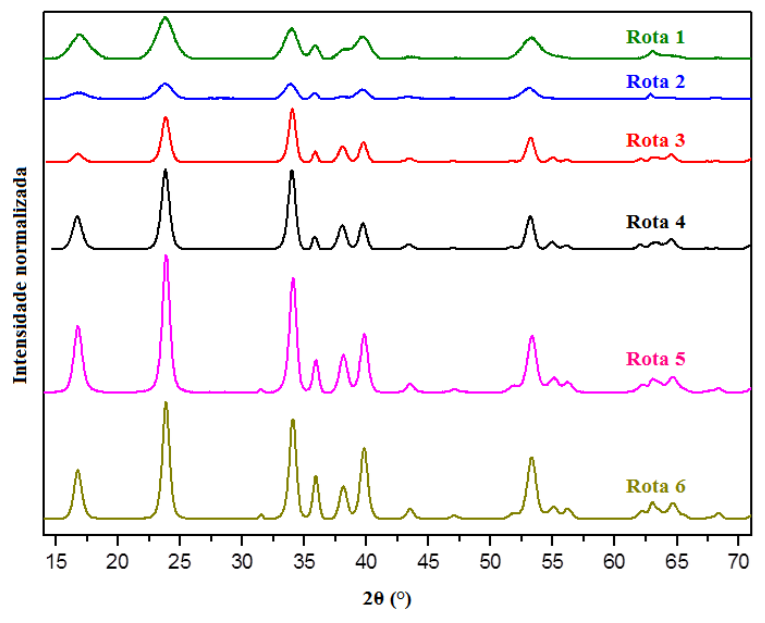

Figura 2: Difratogramas de raios-X dos seis produtos.

Nota-se nas curvas de TG que os produtos das rotas 5 e 6 apresentam maior massa final que os produtos 3 e 4 , que possuem maior massa que os produtos das rotas 1 e 2. Isso sugere que a estabilização do $\mathrm{Cu}(\mathrm{OH})_{2}$ é promovida pela $\mathrm{NH}_{3}$ e pela força do campo ligante do contra-íon: como o $\mathrm{Cl}^{-}$é um ligante mais fraco que o $\mathrm{SO}_{4}{ }^{2-}$, os produtos 5 e 6 os mais estáveis. Isso pode ser verificado nos difratogramas de raios- $X$, uma vez que os produtos 5 e 6 apresentam a maior cristalinidade dentre os demais. De fato, enquanto os produtos das rotas $1 \mathrm{e}$ 2 permanecem na fase $\mathrm{Cu}(\mathrm{OH})_{2}$ por até três semanas, os produtos 5 e 6 permanecem na fase metaestável por até dois meses.

Os difratogramas apontam a fase ortorrômbica do $\mathrm{Cu}(\mathrm{OH})_{2}$ para todos os produtos. É importante ressaltar que não foram observados indícios de impurezas nem nas curvas de TG nem nos difratogramas, indicando a eficiência das rotas na obtenção de produtos puros.

\section{Conclusões}

As rotas se mostraram eficientes na produção do $\mathrm{Cu}(\mathrm{OH})_{2}$ pureza e estabilidade satisfatórias. A presença de $\mathrm{NH}_{3}$, aliada à temperatura e à força do campo ligante do contra-íon, são os principais fatores responsáveis pela estabilidade e cristalinidade do material.

\section{Agradecimentos}

Os autores agradecem à FAPES (\#63700921) pelo apoio financeiro e ao Laboratório de Raios-X - Núcleo de Competências em Química do Petróleo, UFES.

\section{Referências}

1 - Guanhua Lin, Wenfeng Jia, Wensheng Lu, Long Jiang. Journal of Colloid and Interface Science 353, 392-397, 2011.

2 - Abd El-sadek M S, Moorthy Babu, S. Journal of Solid State Chemistry 184, 1135-1140, 2011.

3 - Conghua Lu, Limin Qi, Jinhu Yang, Dayong Zhang, Nianzu Wu, Jiming Ma. J. Phys. Chem. B 108, 1782517831, 2004.

4 - Cudennec Y, Lecerf A. Solid State Sciences 5, 14711474, 2003.

5 - Henry M, Bonhomme C, Livage J. Journal of Sol-Gel Science and Technology 6, 155-167, 1996. 